\title{
Family Medicine Physicians' Views of How to Improve Chronic Pain Management
}

\author{
Linda Garufi Clark, MD, and Carole C. Upshur, EdD
}

Purpose: To determine family practice provider views of how to improve chronic nonmalignant pain (CNMP) management in primary care.

Methods: Modified Delphi group process with providers randomly selected from 6 community practice sites: 3 federally qualified community health centers, 1 rural health center, and 2 hospital-owned practices. Providers gave structured written feedback in response to a report of provider and patient concerns about the quality of CNMP in their practice sites and participated in a facilitated discussion in 1 of 3 group meetings.

Results: $54 \%$ participation $(n=14)$ of family physicians, 6 to 30 years out of residency, identified 4 major themes for improvement of CNMP treatment: (1) the need for provider practice guidelines; (2) changes in the monthly opioid prescription refill process; (3) provision of self-management support and access to alternative treatments for patients; and (4) the use of a nurse care manager.

Conclusions: Family physicians identified multiple components of practice that would improve both provider and patient experiences during and outcomes of CNMP management. Recommendations lend themselves to consideration of CNMP as a chronic illness and use of the Chronic Care Model as an appropriate framework for quality improvement. (J Am Board Fam Med 2007;20:479-482.)

Chronic nonmalignant pain (CNMP) is pain that persists longer than the normal healing time and lasts 3 months or more. ${ }^{1}$ It encompasses multiple diagnoses (most commonly back and other musculoskeletal complaints). Studies have estimated the prevalence of adult chronic pain complaints as affecting $7 \%$ to $55 \%$ of the population ${ }^{2,3}$ and affecting 1 in 3 American adults during their lifetimes. ${ }^{3}$ Most chronic pain care occurs in primary care settings. ${ }^{4}$ Although the identification of pain has been recognized as the 5 th vital $\operatorname{sign}^{5}$ and appropriate

This article was externally peer reviewed.

Submitted 27 January 2007; revised 8 May 2007; accepted 16 May 2007.

From the Department of Family Medicine and Community Health, University of Massachusetts Medical School, Boston.

Funding: Grant 1 R03 HS013455-01A1 from the Agency for Health Care Research and Quality.

Prior presentations: This work was presented at the 2006 HMO Research Network Annual Conference, Cambridge, MA, 2006 May 3; the Society of Teachers of Family Medicine NorthEast Region Meeting, Danvers, MA, 2006 October 28; the American Public Health Association's 134th Annual Meeting, Boston, MA, 2006 November 7; and the North American Primary Care Research Group. Quebec City, Quebec, Canada, 2005 October 16.

Conflict of interest: none declared.

Corresponding author: Linda Garufi Clark, MD, Family Health Center of Worcester, 26 Queen Street, Worcester, MA 01610 (E-mail: Linda.ClarkFHCW@umassmed.edu). pain management for those with terminal illness has improved, challenges continue about how to treat CNMP. ${ }^{6,7}$ These include concerns about prescribing opioids because of the potential for patient misuse of controlled substances, as well as law enforcement scrutiny of providers. ${ }^{6-8}$ Studies have also shown that providers feel inadequately trained to treat CNMP and are dissatisfied with providing care for this patient population. ${ }^{8-10}$ The current study was undertaken to elicit provider views about how to improve CNMP treatment in primary care.

\section{Methods}

The study was approved by the Institutional Review Board of the University of Massachusetts Medical School. A random selection of family physicians from each of 6 practices was invited to attend 1 of 3 group meetings led by the second author (CCU). A modified Delphi technique was used to solicit "expert opinion" about how to improve chronic pain treatment. The Delphi technique is a systematic approach to elicit information for needs assessment and program planning. ${ }^{11,12}$ The groups were first presented with results from previous surveys about CNMP from providers and patients. ${ }^{10}$ Each participant was then asked to complete a written worksheet. On one side, providers 
were directed to respond with the single most important support they personally needed to improve their chronic pain care, followed by a specific educational, a resource, and an office system change (totaling 3) from which they would benefit. The second side repeated these categories but asked providers to identify the single most important change to benefit patients, and then an improvement patients needed in each of the 3 subcategories of education, support, or office systems.

Each provider was then asked to read their responses out loud. An overall discussion was conducted to further explore provider responses, and the session concluded with a respondent confirmation exercise to clarify consensus/minority views on final themes. Groups were audio taped and flip chart notes were used to record the discussion. A total of 26 providers were invited to attend sessions; $54 \%(\mathrm{n}=14)$ participated (although 2 providers were diverted from the discussion part of the groups because of urgent last-minute conflicts). Participants' represented 6 ethnically and economically diverse community practice sites, including 3 urban Federally qualified community health centers, 2 urban university-based practices, and a rural family medicine practice in Massachusetts. Participants included 10 male and 4 female family practice providers, in practice for 6 to 30 years. The authors independently identified themes derived from the written worksheets, flip charts, and audio tapes. Qualitative software was not used and themes were not preidentified. The authors then compared themes, refined and created new categories, and resolved conflicts. Final triangulation was conducted by presenting the themes to a physician coinvestigator who participated only as an observer, not as a contributor to the group discussion. ${ }^{13}$

\section{Results}

Four overarching themes emerged across all groups and respondents: (1) the need for a physician practice guideline tool kit with a range of information, but particularly around opioid prescribing; (2) changes in the way patients obtain monthly medications; (3) improvements in patient self-management education and increased access to both providers and alternative interventions; and (4) the importance of a nurse care manager to collaborate with both providers and patients. All physicians agreed that having informational resources in the form of a chronic pain template or toolkit would help them improve their care. Different providers identified somewhat different materials they would include in such a toolkit, but suggestions included a history tool that screened for potential addiction problems, model opioid contracts, analgesic flow sheets, evidence-based treatment guidelines, and contact information for local resources such as pain clinics and behavioral health services.

Ideas about physician education included casebased workshops, information about opioid pharmacology, screening for medication misuse, stateof-the art interventions, community resources, developing physical assessment skills, and role-play around setting limits. Other ideas mentioned included seeing patients jointly with a pain specialist and having a case review group including primary care physicians and specialists. Another suggestion was educational sessions for office staff, such as how to deal with disruptive patient behavior. Participants felt they would benefit from the support of a care manager to manage prescription refills and patient communication. Support was also sought in having better access to specialists to assist with diagnosis and management.

In regards to office systems changes, all 3 groups nominated the importance of a redesigned opioid refill process to benefit providers and patients. The requirement that patients on chronic opioid maintenance pick up a monthly refill script was reported to cause tremendous anxiety and conflict for both patients and providers. Physicians reported they felt "chased" and "hounded" by patients. Practice partners also sometimes changed dosing or refused to prescribe because of differences of agreement in philosophy about opioid treatment for CNMP. Providers thus wanted a better system, such as routine times or a specific designated person to dispense scripts. Other refill improvements included using a care manager, starting a patient registry, and implementing electronic tracking mechanisms to monitor refills. Some felt that open access follow-up appointments or asynchronous communication between primary care physicians and patients, such as e-mail, would also help.

When asked to list the one overall intervention primary care physicians felt would most benefit patients, all 3 groups strongly identified the need for patients to have improved access to medication refills. Reduced barriers to communication with their primary care physician and access to afford- 


\begin{tabular}{|c|c|c|c|c|c|c|}
\hline & Leadership & $\begin{array}{l}\text { Decision } \\
\text { Support }\end{array}$ & $\begin{array}{l}\text { Practice } \\
\text { Redesign }\end{array}$ & $\begin{array}{c}\text { Clinical } \\
\text { Information } \\
\text { Systems }\end{array}$ & $\begin{array}{c}\text { Patient Self- } \\
\text { Management } \\
\text { Support }\end{array}$ & $\begin{array}{c}\text { Community } \\
\text { Resources }\end{array}$ \\
\hline Provider toolkit & & $\begin{array}{l}\text { Guidelines on } \\
\text { assessment, } \\
\text { prescription, } \\
\text { documentation }\end{array}$ & & $\begin{array}{l}\text { Registry and } \\
\text { treatment } \\
\text { documentation } \\
\text { system }\end{array}$ & & $\begin{array}{l}\text { Referral and } \\
\text { specialty } \\
\text { resources }\end{array}$ \\
\hline $\begin{array}{c}\text { Patient supports } \\
\text { and resources }\end{array}$ & & $\begin{array}{l}\text { Opioid } \\
\text { contracts }\end{array}$ & $\begin{array}{l}\text { Provide a care } \\
\text { manager }\end{array}$ & & $\begin{array}{l}\text { Group visits, } \\
\text { materials, } \\
\text { and } \\
\text { education }\end{array}$ & $\begin{array}{l}\text { Alternative } \\
\text { treatments }\end{array}$ \\
\hline $\begin{array}{l}\text { Prescription } \\
\quad \text { refill changes }\end{array}$ & $\begin{array}{l}\text { Gain practice- } \\
\text { wide } \\
\text { acceptance of } \\
\text { guidelines }\end{array}$ & & $\begin{array}{l}\text { Make it routine, } \\
\text { easier, and more } \\
\text { predictable }\end{array}$ & Track refills & & \\
\hline Care manager & & & $\begin{array}{l}\text { New role in practice } \\
\text { to serve as } \\
\text { intermediary to } \\
\text { PCP }\end{array}$ & & $\begin{array}{l}\text { Provide } \\
\text { support and } \\
\text { education }\end{array}$ & $\begin{array}{l}\text { Refer and help } \\
\text { link to } \\
\text { community } \\
\text { resources } \\
\text { and } \\
\text { alternative } \\
\text { treatment }\end{array}$ \\
\hline
\end{tabular}

CNMP, chronic nonmalignant pain; PCP, primary care physician.

able and culturally sensitive treatment modalities other than medication were other ideas. (Each of these ideas are highly concordant with what patients expressed in the patient focus groups. ${ }^{14}$ ) Most felt that a nurse care manager would be a key resource for both patients and providers. Affordable alternative treatments suggested by the primary care physicians, ideally located at the primary care site, included behavioral health, physical therapy, supervised exercise, massage, and chiropractors.

All 3 groups identified educational interventions to help patients develop self-management skills via group sessions and take-home materials. Educating patients about the disease process of chronic pain and the limitations of medical treatment were also mentioned. Some providers also thought patients needed to be oriented to the office systems and legal requirements for controlled substances so that they would better understand the constraints providers operated under.

\section{Discussion}

Family medicine physicians from 6 community practice sites participating in a modified Delphi group process nominated a fairly specific set of improvements they thought would benefit both providers and patients coping with CNMP. These included provider education and resources (toolkit, referral resources); patient self-management educa- tion and alternative interventions (group education sessions, care management, access to exercise, massage, etc); system changes around opioid refills; and the use of a care manager to help coordinate many of these activities. Providers acknowledged that additional health care and patient resources might be needed to comprehensively address improvements in CNMP management, but they also felt some specific low-cost practice redesign issues could result in quality enhancement.

Interestingly, although not consciously proposing that chronic pain may need to be treated similarly to other chronic illnesses, many of the suggestions given by providers in this study fit into the framework of a formal "chronic care model" (CCM) (see Table 1). Wagner et $\mathrm{al}^{15}$ have written extensively about the CCM and its effectiveness in improving patient outcomes for chronic conditions such as diabetes, hypertension, and depression. The CCM includes a systematic approach to proactive management of patients with chronic conditions and includes 6 elements: leadership, decision support, practice redesign, clinical information systems, patient self-management support, and community resources. No evidence that the CCM has been tested with patients with CNMP could be found in the current literature, but this study suggests that further development of a CCM approach to treating CNMP may be a useful way to improve 
both provider and patient challenges in achieving adequate management of CNMP.

Our study was designed to generate ideas for practice improvement for the management of CNMP across multiple, diverse primary care settings (hospital-based, Federally qualified health centers, and rural clinics). Limitations included the relatively small sample size and modest response rate, as well as the geographic location of the practice settings (all in the same state). However, our participation rate reflects the typical physician survey response rate in the published literature, ${ }^{16}$ even though the burden of participation was considerably higher (eg, an evening meeting and travel time). In addition, the concerns raised by our sample members were quite similar to the published literature from other parts of the country regarding the challenges of treating CNMP. ${ }^{6-9}$ Our findings suggest that both patients and primary care physicians will benefit from further study into the application of the CCM to the care of patients with CNMP.

\section{References}

1. International Association for the Study of Pain. Classification of chronic pain. Pain 1986;3(Suppl):S1S226.

2. Blyth FM, March LM, Nicholas MK, Cousins MJ. Self-management of chronic pain: a populationbased study. Pain 2005;113:285-92.

3. Smith BH, Elliott AM, Chambers WA, Smith WC, Hannaford PC, Penny K. The impact of chronic pain in the community. Fam Pract 2001;18:292-9.

4. Khouzam RH. Chronic pain and its management in primary care. South Med J 2000;93:946-52.

5. Joint Commission on Accreditation of Healthcare Organization. 2004 Comprehensive Accreditation Manual for Ambulatory Care, PC-17.
6. Green CR, Wheeler JRC, Marchant B, LaPorte F, Guerrero E. Analysis of the physician variable in pain management. Pain Med 2001;2:317-27.

7. Glajchen, M. Chronic pain: treatment barriers and strategies for clinical practice. J Am Board Fam Practice 2001;14:211-8.

8. Potter M, Schafer S, Gonzalez-Mendez E, Gjeltema K, Lopez A, Croughan-Minihane M. Opioids for chronic nonmalignant pain: attitudes and practices of primary care physicians in the UCSG/Stanford Collaborative Research Network. J Fam Pract 2001;50: 145-51.

9. Bendsen P, Hensing G, Ebeling C, Schedin A. What are the qualities of dilemmas experienced when prescribing opioids in general practice? Pain 1999;82: 89-96.

10. Upshur C, Luckmann R, Savageau J. Primary care provider concerns about management of chronic pain in community clinic populations. J Gen Intern Med 2006;21:652-5.

11. Delbecq AL, Van de Ven AH. A group process model for problem identification and program planning. J Appl Behav Sci 1971;7:466-92.

12. Dalkey NC, Helmer O. An experimental application of the Delphi method to the use of program planning. Manage Sci 1963;9:458-67.

13. Kruger RA. Analyzing and reporting focus groups. Thousand Oaks (CA): Sage Publications; 1998.

14. Bacigalupe G, Upshur C, Gorlier JC, Gallagher P. Good clinical encounters in primary care: chronic pain patients' views of the doctor-patient relationship. Ann Behav Med 2005;29(Suppl): S128.

15. Wagner EH, Austin BT, Davis C, Hindmarsh M, Schaefer J, Bonomi A. Improving chronic illness care: translating evidence into action. Health Aff 2001;20:64-78.

16. Field TS, Cadoret CA, Brown ML, et al. Surveying physicians: do components of the 'total design approach' to optimizing survey response rates apply to physicians. Med Care 2002;40:596-606. 